\title{
REPARACIÓN DE UNA CONSTRUCCIÓN EXPERIMENTAL
}

\author{
(A REPAIR IN AN EXPERIMENTAL BUILDING CONSTRUCTION)
}

José Luis Pérez Freire, Arquitecto

193-24

Fecha de recepción: 9-1X-1989

\begin{abstract}
RESUMEN
Se describe en este artículo un sistema experimental de construcción de viviendas, objeto de un Concurso de ideas en el que se trataba de obtener soluciones alternativas a la construcción tradicional mediante el empleo de productos y métodos industriales.
\end{abstract}

El resultado fue la construcción de 866 viviendas en bloque y unifamiliares en un tiempo récord, utilizando la propuesta que obtuvo el primer premio.

\begin{abstract}
SUMMARY
An experimental building system is the subject described in this article.

How to get better solutions to the traditional construction systems in housing, was the theme of a competition of projets in wich the use of industrial products and proceedings was the main intention.
\end{abstract}

The result of this work, winner in the competition, was the construction of 866 housing of two typologies, compact and single, in a very brief time in Spain.

\section{INTRODUCCIÓN}

Si el término Arquitectura es considerado - dentro de los procesos de producción del hombre-como un producto a alcanzar, no se puede prescindir de todas las circunstancias que permiten que las construcciones se configuren materialmente gracias a la existencia de un largo proceso creativo anterior, colmado de intenciones y reflexiones.

Profesionalmente, la Arquitectura viene vinculada a la práctica edificatoria, y no se puede materializar más que con los conocimientos que diferencian a la edificación de otras actividades de producción. Esto es: unos determinados conocimientos y una adecuada habilidad para poder especificamente concretar. Por encima de estos conocimientos se encuentra la experiencia edificatoria.

Estas reflexiones, bien conocidas, han sido expuestas desde siempre. Incluso Vitrubio nos recuerda los contenidos que la Arquitectura debe poseer. Las construcciones han de ser - dice- "Firmitas, Utilitas y Venus- tas"; las edificaciones han de poseer la cualidad de firmes, útiles y bellas y las tres al tiempo. Sin embargo, para que las construcciones sean útiles y bellas tendrán que ser primero firmes, resistentes, duraderas, etc., de lo contrario nunca podrán tener vida; nunca podrian existir.

Esto hace que el profesional otorgue dicha cualidad al objeto arquitectónico, en el momento de su concepción, cuando trata de establecer condiciones para que la obra responda con una cierta calidad edificatoria, formulándose preguntas muy similares a las siguientes: ¿Se podrá dañar el edificio? ¿Cuáles serán las causas? ¿Cómo diseñarlo para evitarlas? ¿Cuándo se producirán las agresiones? ¿En qué grado y cómo preverlo?, etcétera. Hoy estas preguntas con sus respuestas $-y$ muchas más- están perfectamente sistematizadas, incluso concatenadamente.

La técnica edificatoria con los modelos de comportamiento existentes - sobre todo en el campo de los prefabricados - dan, en la mayoria de los casos, inmediata respuesta a muchas de estas cuestiones. 


\section{ANTECEDENTES}

¿Qué pensaríamos si, a través de un encargo profesional, nos encontrásemos con una edificación deteriorada, cuyo origen estuviera caracterizado por una construcción experimental que sirvió para iniciar, por parte de la Administración, el empleo de la industrialización y prefabricación en la construcción de viviendas?

En principio seguramente podria pensarse que, en determinadas condiciones, tanto económicas como técnicas, no debieron ser tan fáciles ni tan sencillas de formalizar, ni de contestar, como algunas de hoy. $Y$ puede que surgieran otras cuestiones mucho más complicadas para su tiempo.

En 1987 se nos encargó, por parte del I.V.I.M.A., la redacción de un Proyecto para acometer las reparaciones de las viviendas situadas en la calle Camino Viejo de Leganés, 93, 93 duplicado y 93 triplicado de Madrid.

La edificación pertenece a uno de los Proyectos que formaron el "Concurso de Viviendas Experimentales", promovido en 1957 por el entonces Instituto Nacional de la Vivienda. Por aquel entonces, parte del mismo - seis de los treinta y cuatro grupos que formaban el conjunto de las distintas empresas y arquitectos del pais - fue publicado en la Revista Nacional de Arquitectura (Nota 1 a pie de página, concretamente en los números 193, 194 y 195, correspondientes a los meses de enero, febrero y marzo de 1958). Posteriormente, la Revista ARQUITECTURA (Nota 2 a pie de página, el número 2, correspondiente a febrero de 1959) recogió otra de las actuaciones realizadas en el Certamen:

"...El Instituto Nacional de la Vivienda, buscando la adaptación de las técnicas modernas a la construcción de las viviendas, inició en el año 1943 la experiencia de lograr sistemas constructivos que abaratasen los costos de dichas obras. Sin embargo, este intento no pudo llevarse a cabo por las exigencias de tener que realizarse sólo en aquellos Ayuntamientos que cediesen gratuitamente los terrenos.

De nuevo el Instituto Nacional de la Vivienda vuelve a intentarlo - pero esta vez en una zona prefijada de Madrid-, en 1957, por medio de un concurso cuya finalidad es estudiar y comparar técnicas constructivas sobre una base común de un mismo proyecto. Se trataba, por consiguiente, de un concurso de procedimientos constructivos para un mismo Proyecto de viviendas.

Sin embargo, estos planteamientos fueron modificados por los propios concursantes, transformándose en un concurso de arquitectura, con proyectos diferentes, de acuerdo con cada arquitecto/s, que realizaron distintas empresas constructoras. No fue, por tanto, posible la comparación para un mismo proyecto de diferentes ti- pos de construcción, sino de la construcción de diferentes tipos de casas.

Pero, aun en estas condiciones, en el Certamen cada tándem arquitecto/s-constructor expuso su opinión sobre la vivienda e industria de la edificación, para po. ner a punto y realizar a escala industrial la construcción de viviendas proyectadas y ejecutadas con sistemas constructivos, con los que se llegase a mejores soluciones y más económicas que las obtenidas en la construcción tradicional, tanto constructivas con un intento de un gran avance en la industrialización, como en aquéllas resueltas mediante soluciones apoyadas en la construcción tradicional, ofrecieron y aún hoy ofrecen un estudio a realizar en profundidad de indudable interés.

De todos modos, el resultado del Concurso fue que, en un plazo increiblemente breve en la escala española, se han levantado 866 viviendas (tanto en soluciones de bloque, como de viviendas unifamiliares) en una unidad vecinal, hoy incompleta porque no dispone de la edificación complementaria que requiere un conjunto de 6.000 habitantes..."

\section{DESCRIPCIÓN DEL EDIFICIO}

\section{Cuestiones generales y formales}

La edificación objeto de nuestro estudio era el número 46 en el plano general de situación del CONCURSO DE VIVIENDAS EXPERIMENTALES. LOS responsables de la misma fueron los Arquitectos SAIZ DE VICUÑA y ESCOLA. La realización de las obras corrió a cargo de la Empresa E. VELAZQUEZ.

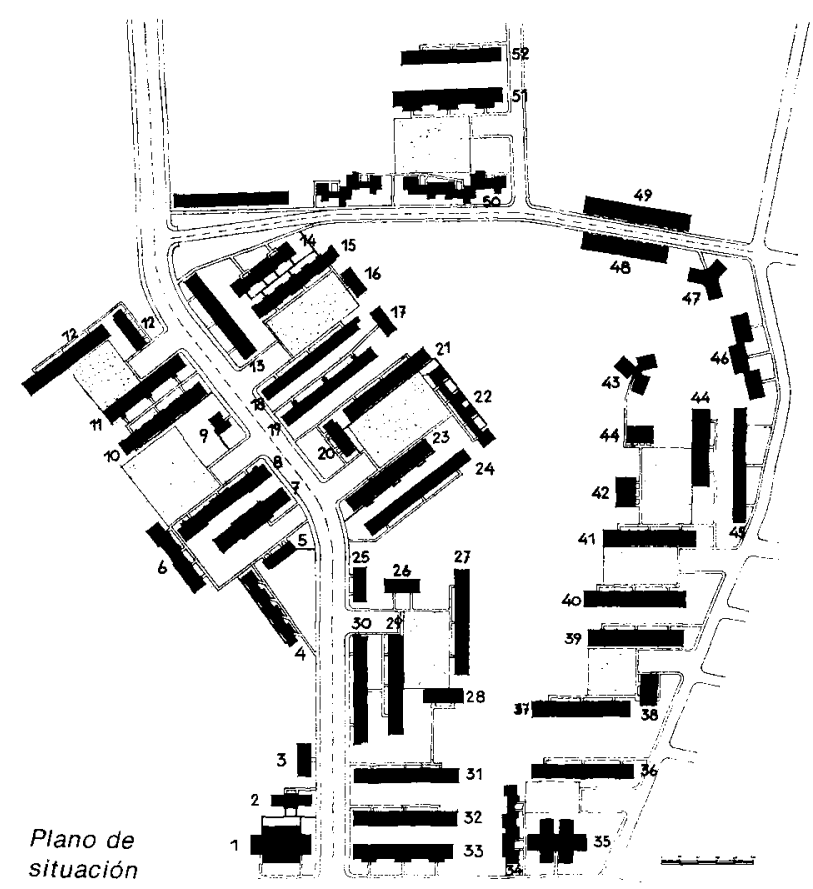




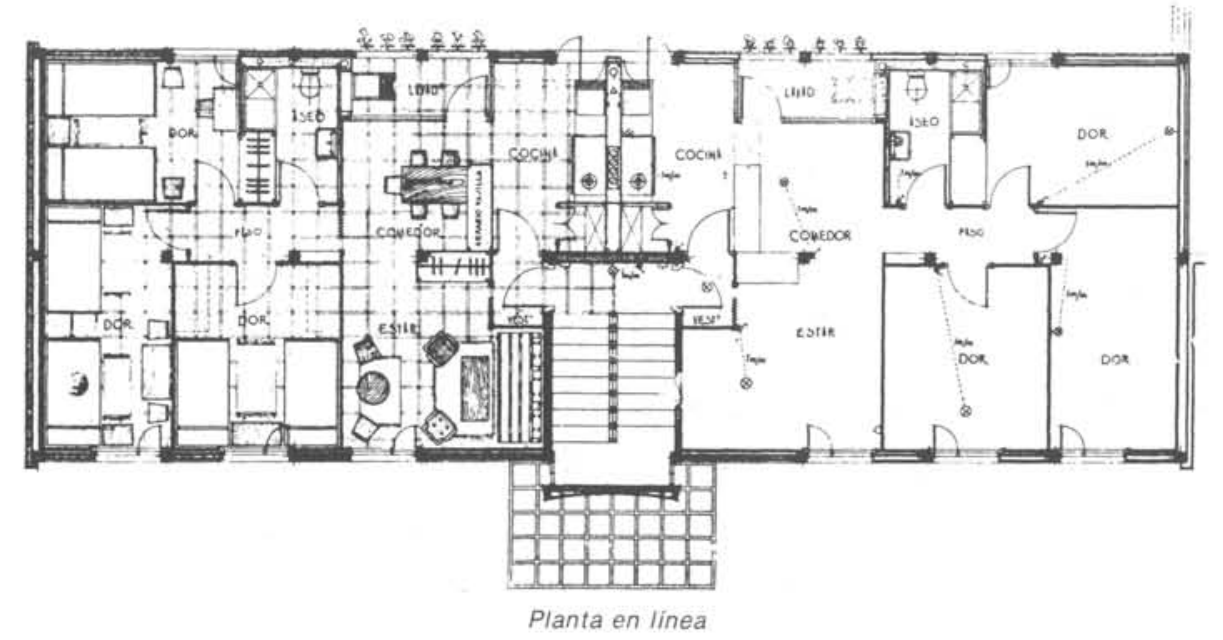

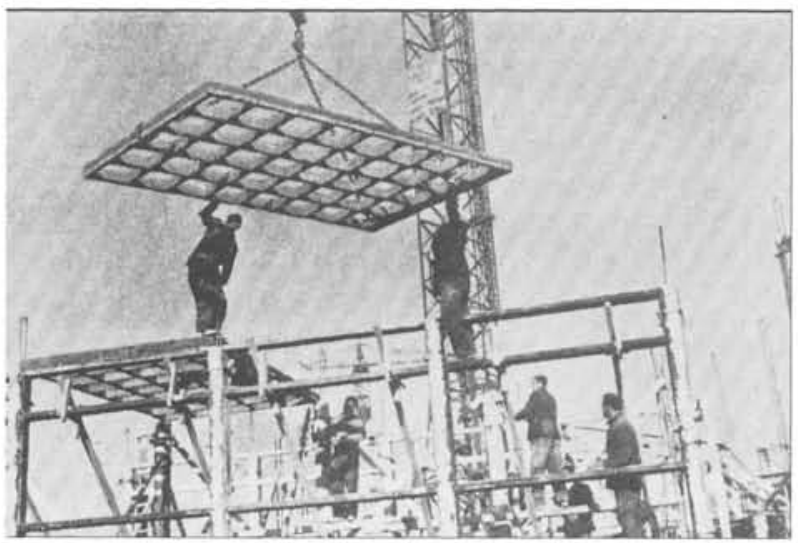

Foto 1.-Disposición del forjado. Los pasos de instalaciones se ejecutan mediante rotura. Inexistencia de cargaderos en los muros de carga interiores.

Foto 2.-Algunas losas manifestaban lo que habia sucedido de una

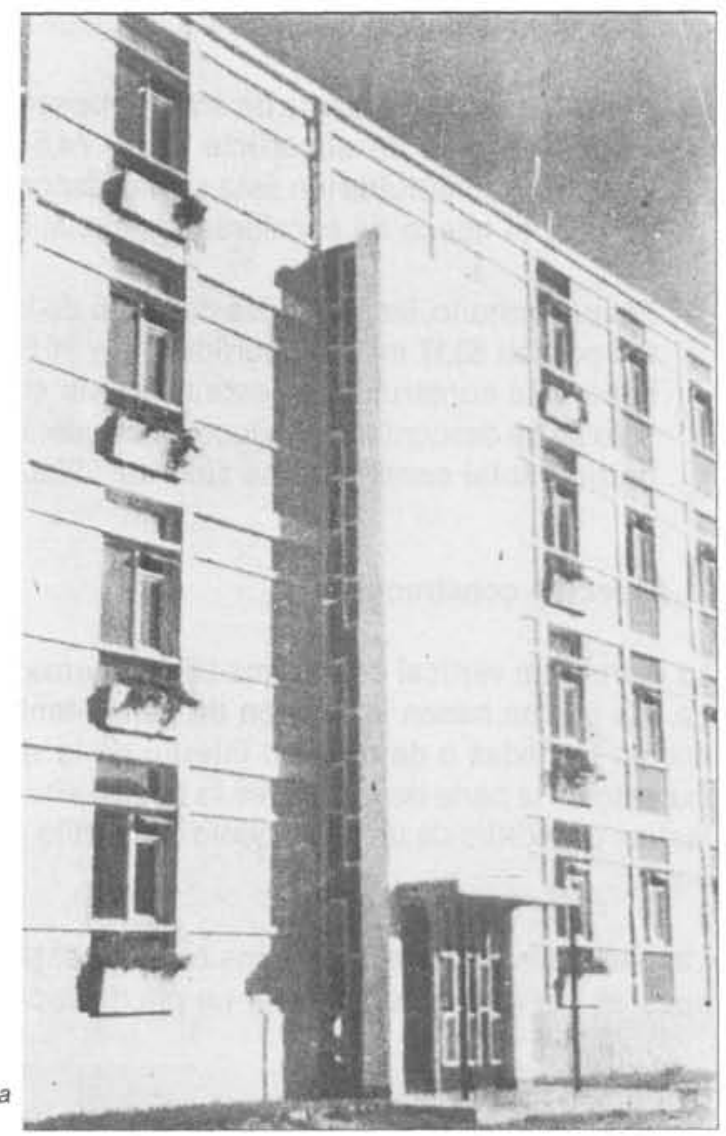
forma escandalosa.

La obra está constituida no por un único bloque independiente, sino por tres adosados entre si a través de sus testeros. El bloque central está invertido en su posición con respecto a los otros, diferenciándose de ellos mediante un retranqueo en la alineación de sus fachadas.

Una de las cosas que más llama la atención es la disposición geométrica de los volúmenes. Lo que permitió ese desfase en la edificación de los bloques fue una mayor dimensión en su profundidad permitiendo, por tanto, alcanzar una mayor superficie. Esta serie de condiciones facilitaron que la disposición de habitaciones, entre las que se sitúan en las fachadas principales, fueran dotadas de iluminación y ventilación a través de los muros laterales.

El acceso a cada uno de los bloques se realiza a través de los portales situados en el centro de las fachadas. 
La distribución, tanto de la planta baja como del resto, es simétrica en cada bloque, y coincidente en los tres. Debido a los cambios que los vecinos hicieron, a lo largo del tiempo, en la mayoria de los casos la distribución habia sufrido alguna alteración. Tan sólo una vivienda mantenia la misma distribución original.

Una de las variaciones espaciales, con respecto a la distribución original común (excepto la vivienda que se conserva intacta) en que todos los vecinos acometieron su reforma, consistia en hacer desaparecer - para obtener una cocina más amplia - un armario empotrado que se abria al pasillo y un lavadero al que se accedia por la cocina. Esta recibia la ventilación por la ventana de la terraza.

El conjunto del proyecto alberga una totalidad de 24 viviendas distribuidas en cuatro plantas por bloque y con dos viviendas por cada una de las plantas:

- Las viviendas de la planta de entrada poseen 62,34 metros cuadros de superficie útil y $74,54 \mathrm{~m}^{2}$ de superficie construida (en ésta se ha descontado el portal y el hueco de escalera y descansillo).

- Por el contrario, las viviendas del resto de las plantas poseen $63,17 \mathrm{~m}^{2}$ de superficie útil y $76,00 \mathrm{~m}^{2}$ de superficie construida (en este caso, sin embargo, sólo se ha descontado el hueco de escalera). La superficie total construida ha sido de $1.928,45 \mathrm{~m}^{2}$.

\section{Aspectos constructivos}

La estructura vertical está formada por muros de carga, los cuales hacen la función de cerramiento exterior en fachadas o de división interior de la vivienda, excepto en la parte de terraza, en la que se situaron pilastras de ladrillo de un pie y medio de ladrillo perforado.

Las fachadas de cada uno de los bloques están compuestas por muros de carga de un pie de espesor de

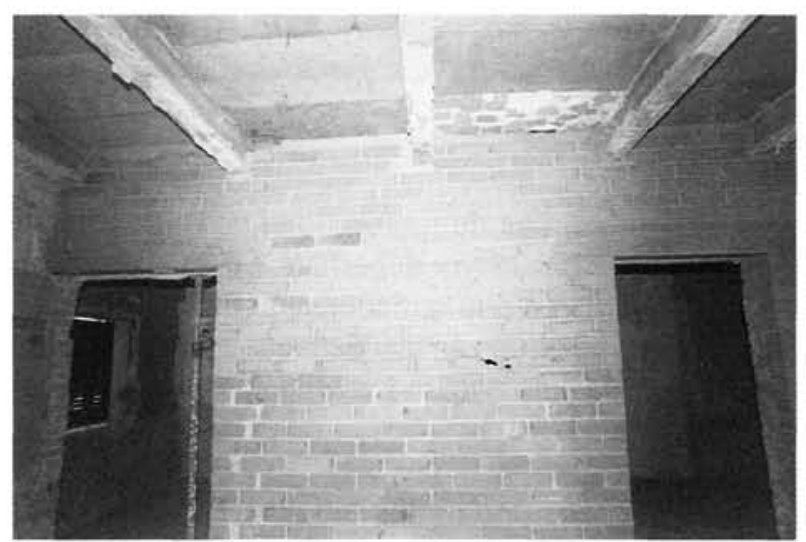

Foto 3.- Los muros interiores se reforzaron a fin de soportar co. rrectamente las solicitaciones. Ver foto 12.

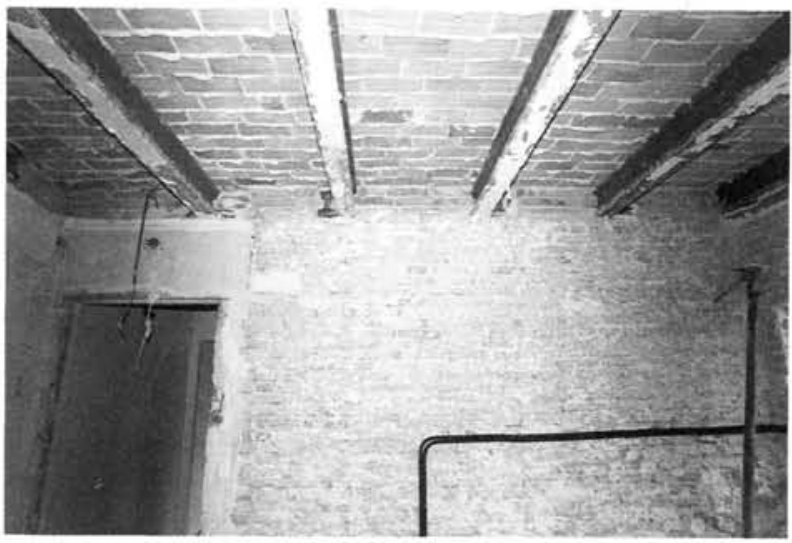

Foto 4.-El forjado de cubierta se concibió más ligero.

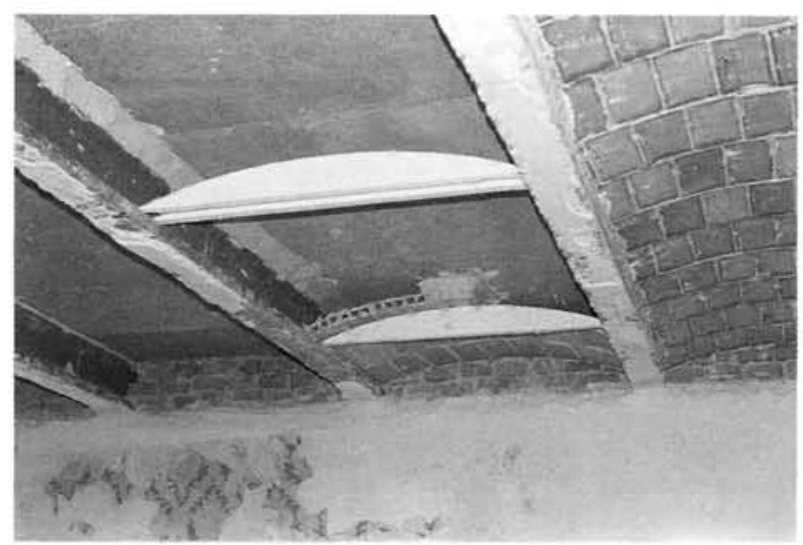

Foto 5.-Modo de ejecución de la reparación de forjados.

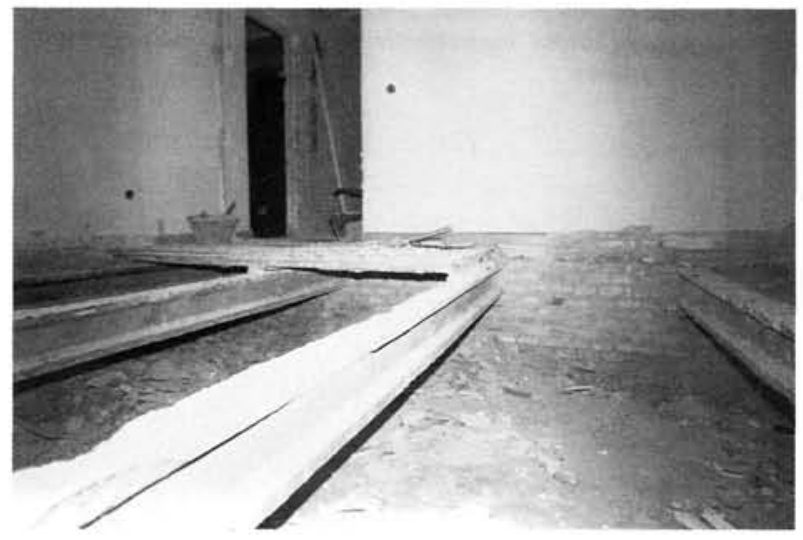

Foto 6.-El forjado de Planta Baja estaba en contacto con el terre. no, formando con él una cámara de aire.

fábrica de ladrillo perforado, enfoscados con mortero de cemento y arena, y pintados de blanco. Los huecos de ventana se producen mediante cargaderos de hor. migón armado, de las mismas características que las viguetas de forjado. Los muros de carga interiores son de medio pie, también de fábrica de ladrillo perforado con acabado en yeso.

La separación entre caras de los diferentes muros de carga es:

http://informesdelaconstruccion.revistas.csic.es 


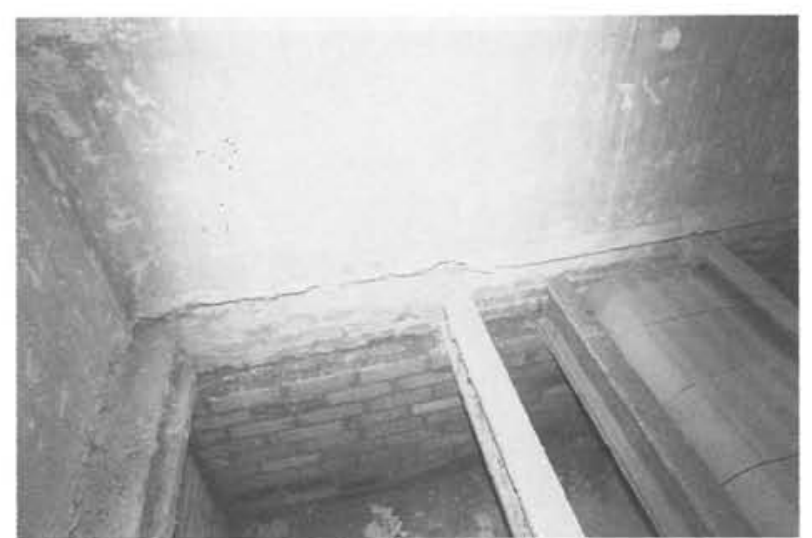

Foto 7.-En el Forjado de Planta Baja, no es viable la solución general al tener que ejecutarse desde abajo.

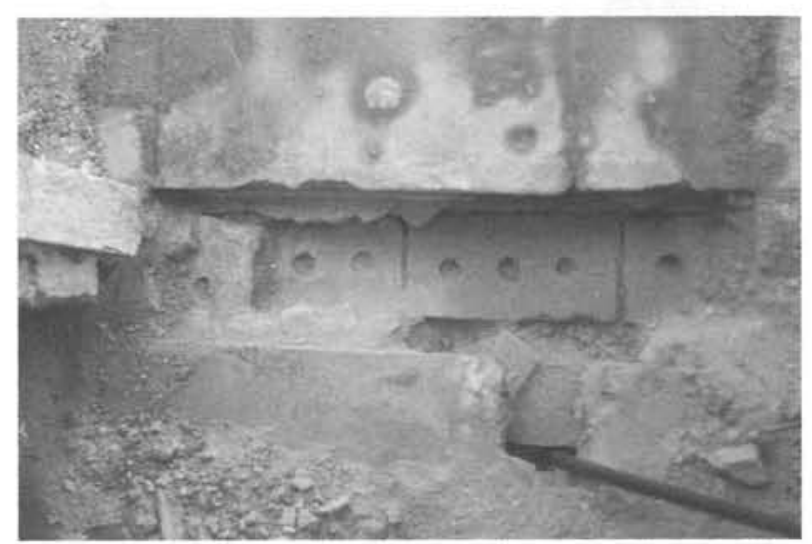

Foto 8.- La modulación alcanza a todos los elementos constructivos.

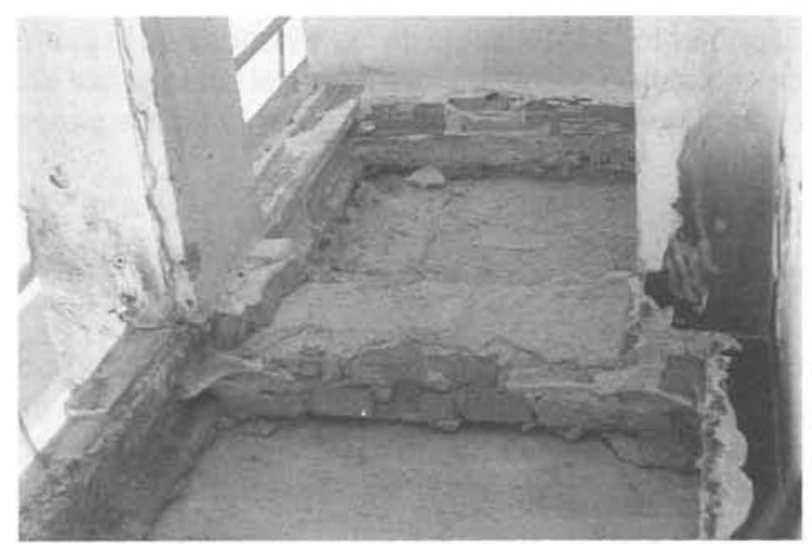

Foto 9.-En la zona de tendederos el sistema era demasiado libre y estaba debilitado. Se zuncharon verticalmente las pilastras y se co. nectaron perpendicularmente a la construcción. Ver fotos 14 y 16 .

- Entre muros de un pie y muros de medio pie, de 3,96 y $3,40 \mathrm{~m}$.

- Entre muros de carga interiores de medio pie, de $3,07 \mathrm{~m}$.

Los forjados constituidos por viguetas autorresistentes de hormigón armado, con un perfil en forma de I, de $19 \mathrm{~cm}$ de canto y $12 \mathrm{~cm}$ de ancho, se ha hecho que apoyen directamente en los muros de carga sin la uti- lización de ningún otro elemento constructivo que sirva para repartir la carga (zuncho, durmiente, etc.), ni para producir un encadenado con todas las viguetas. Sobre las viguetas apoyan unas losas de $104,5 \times 50,5 \mathrm{~cm}$ de dimensión y con un espesor de $5 \mathrm{~cm}$, realizadas en hormigón y armadas con acero en las dos direcciones. El acanalamiento cóncavo, que poseen en su espesor, permitió unirlas entre si mediante cordones de cemento y obtener un machihembrado con objeto de evitar su movimiento. Estas piezas poseen un tratamiento superficial - a base de cemento de unos $5 \mathrm{~mm}$ de espesor, arenas con muy bajo índice de poros para obtener una gran compacidad, y colorante en tono rojizo- que, perfectamente pulido, da el color y el acabado del piso de la vivienda.

Entre las viguetas, en su cara inferior, se sitúa un tablero de rasilla guarnecido y enlucido en yeso que sirve de cielo raso.

Toda la construcción en planta está basada en la modulación de las losetas de hormigón. El ancho de vigueta, $12 \mathrm{~cm}$, permite la compatibilidad en relación a las dimensiones con el ladrillo usado, llegando a situaciones de permitir los desfases entre viguetas y el paso del muro de cerramiento de las cocinas con las terrazas, cuyo muro es de medio pie en ladrillo perforado exteriormente, enfoscado y alicatado en su interior.

La tabiquería está constituida por piezas de escayola del tamaño del hueco sencillo, $24 \times 12 \times 4 \mathrm{~cm}$, sin machihembrar entre ellas (se habian sustituido las piezas de ladrillo por piezas de escayola manteniendo su propia forma, incluso su colocación).

Por delante de las cocinas se ha situado para cada vivienda una terraza tendedero, excepto en la planta de entrada, en las que el acceso del portal les resta su superficie a las viviendas de la planta baja.

Este tendedero, situado encima del hueco del portal, está constituido por dos pilastras de un pie y medio de ladrillo del mismo tipo que el de fachada; entre ellas se sitúa una celosia modulada y prefabricada de hormigón, convencional, apoyada entre forjados. Estas dos pilastras de ladrillo son solidarias con el resto de la construcción a través de viguetas, éstas del mismo tipo que las del forjado, y situadas en el borde de fachada. La cubierta, en su momento, era plana y las bajantes se proyectaron por el interior de las viviendas. Los vecinos la modificaron en cubierta a dos aguas anulando, por tanto, el uso de las bajantes interiores. Las inclinaciones de los faldones se llevaron a cabo con tabiquillos rematando con uralita. Los testeros, adquirian por tanto, la nueva forma del tejado a dos aguas de cada uno de los tres bloques, completando la modificación con el canalón y las bajantes vertiendo directamente al terreno, pudiendo evitar - al modificar la inclinación que tenía hacia la construcción permi- 


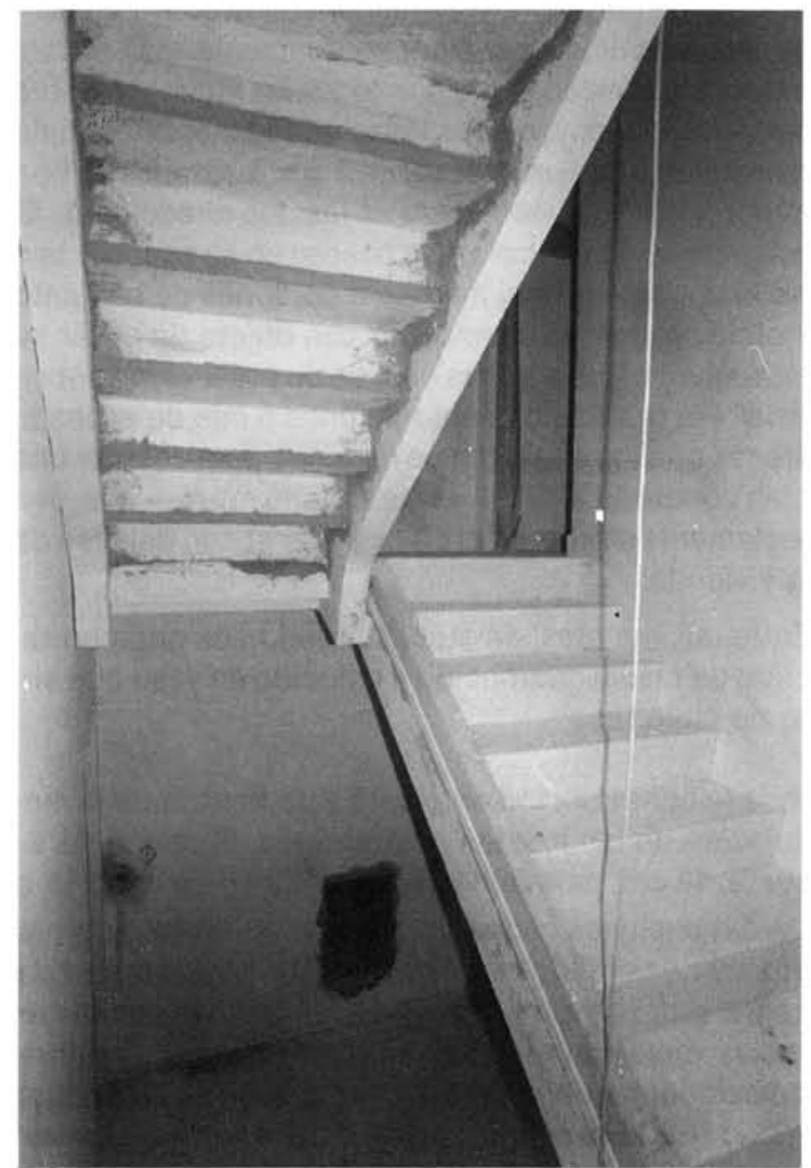

Foto 10.-El nuevo peldañeado se va apoyando en los sucesivos quie bros que posee la zanca de hormigón armado.

tiendo que las fábricas se cargasen de agua- que se produjeran deterioros en la resistencia de las fábricas.

La cubierta original estaba constituida de igual forma que los forjados por viguetas autorresistentes de hormigón armado sustituyendo, entre viguetas, las losetas de hormigón armado por una tablero de rasilla de dos roscas. La cubierta se encontraba impermeabilizada en su superficie.

La escalera tiene dos zancas de hormigón armado, apoyando el peldañeado en paralelo a éstas (las zancas tienen sección en $L$ ) conformado de antemano y constituido por terrazo de china fina; el mismo material sirve para dar el acabado a los descansillos. Recibe la luz a través de unas pequeñas ventanas construidas a base de losetas de pavés fijo y situadas en el muro del hueco de escalera.

La carpintería exterior se ha llevado a cabo en madera, con fraileros metálicos.

La cimentación de los edificios se realizó mediante zanja corrida de hormigón en masa (ciclópeo), asentando sobre terreno de arcilla con una profundidad superior a $1,50 \mathrm{~m}$.

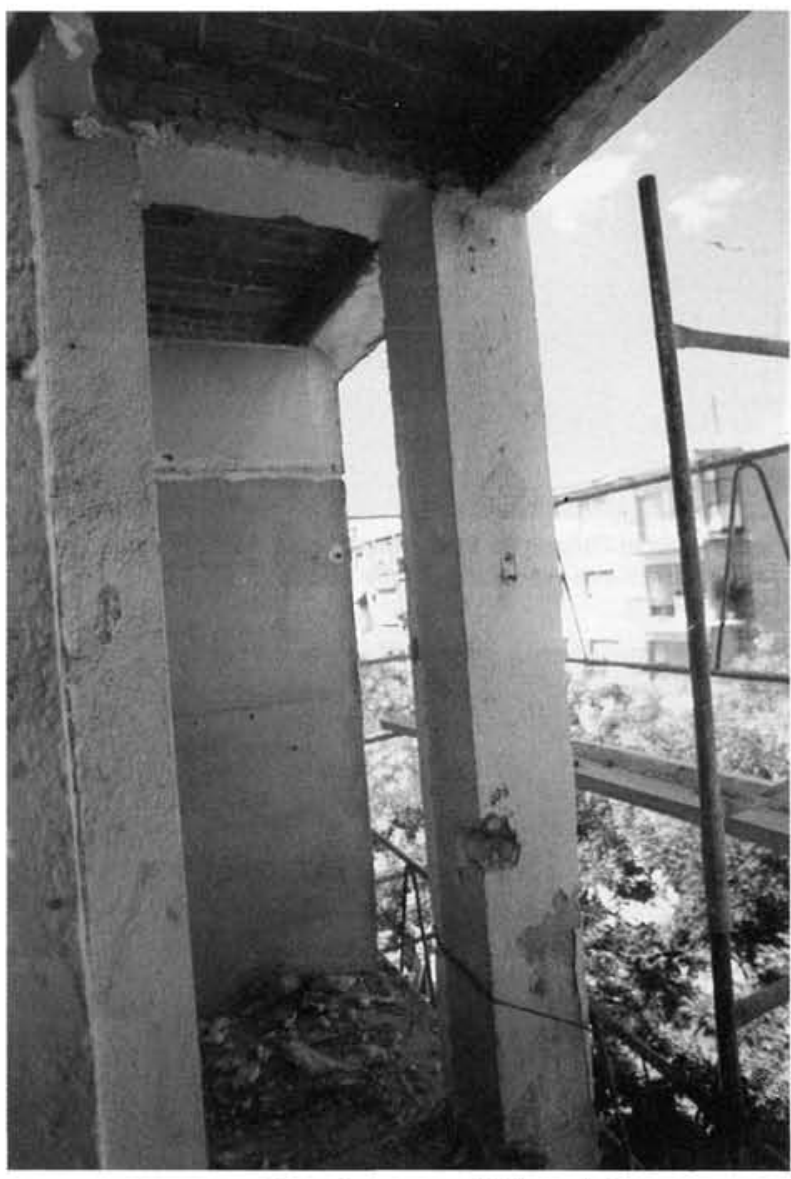

Foto 11.-Zona de terrazas. Ultima planta.

El primer forjado (el suelo de las viviendas de la planta de entrada) se encuentra levantado del suelo, sobre una cámara de aire que permite albergar la red de saneamiento.

\section{DESCRIPCIÓN DE LA ACTUACIÓN}

Con el Proyecto de Reparaciones, llevado a cabo por el I.V.I.M.A., se pretendió acometer y solucionar los daños originados en la totalidad de la construcción mediante una adecuada consolidación, e introducir los elementos de confort que lo hicieran realmente habitable.

La obra, dañada en su totalidad, habia sufrido una degradación paulatina que se manifestaba en toda ella. Esto obligaba a plantearse la consolidación de forma que afectase indefinidamente al edificio, orientándola a la búsqueda de un nuevo estado de equilibrio.

En los objetivos planteados no se consideraba la solución de los problemas concretos de cada material ni sistema de modo independiente, sino más bien la diversidad de los elementos constructivos como si se tratase - de hecho se trata- de un conjunto global, teniendo en cuenta - eso si- la interdependencia entre los elementos constructivos para compatibilizar al 


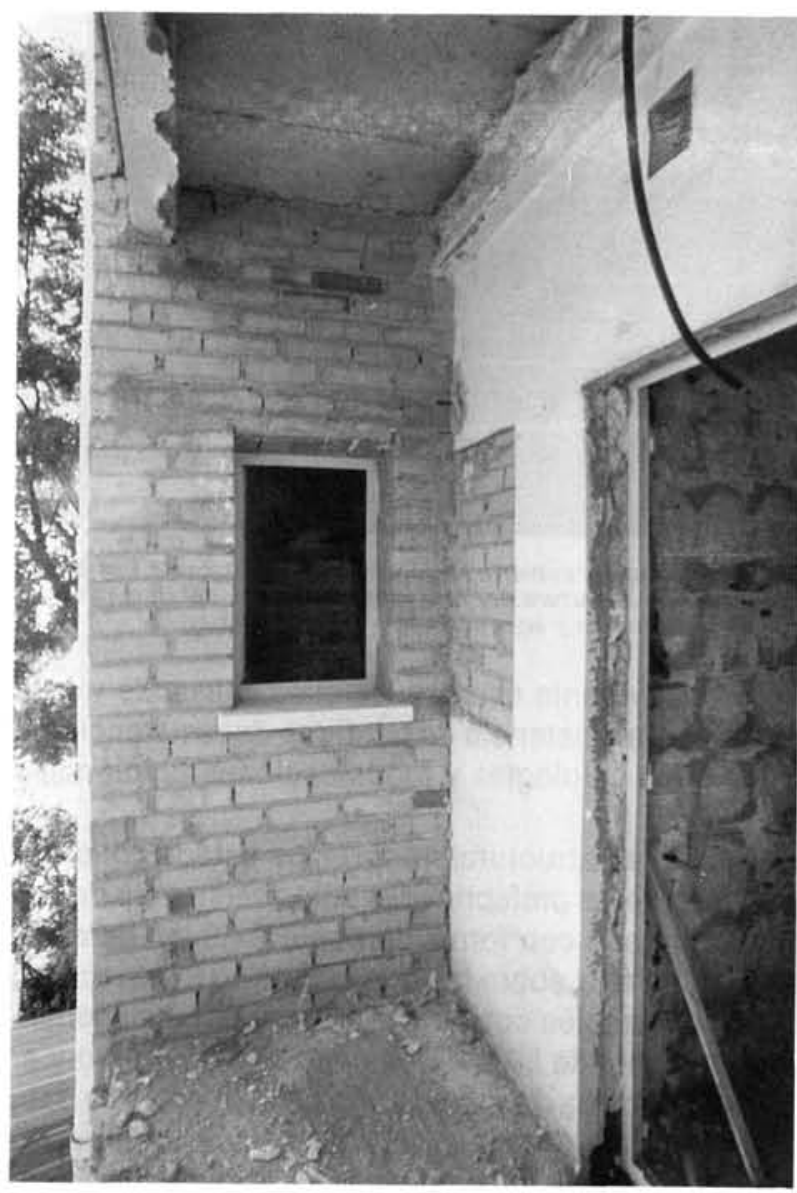

Foto 12.-Refuerzo de muros interiores. Ver foto 3

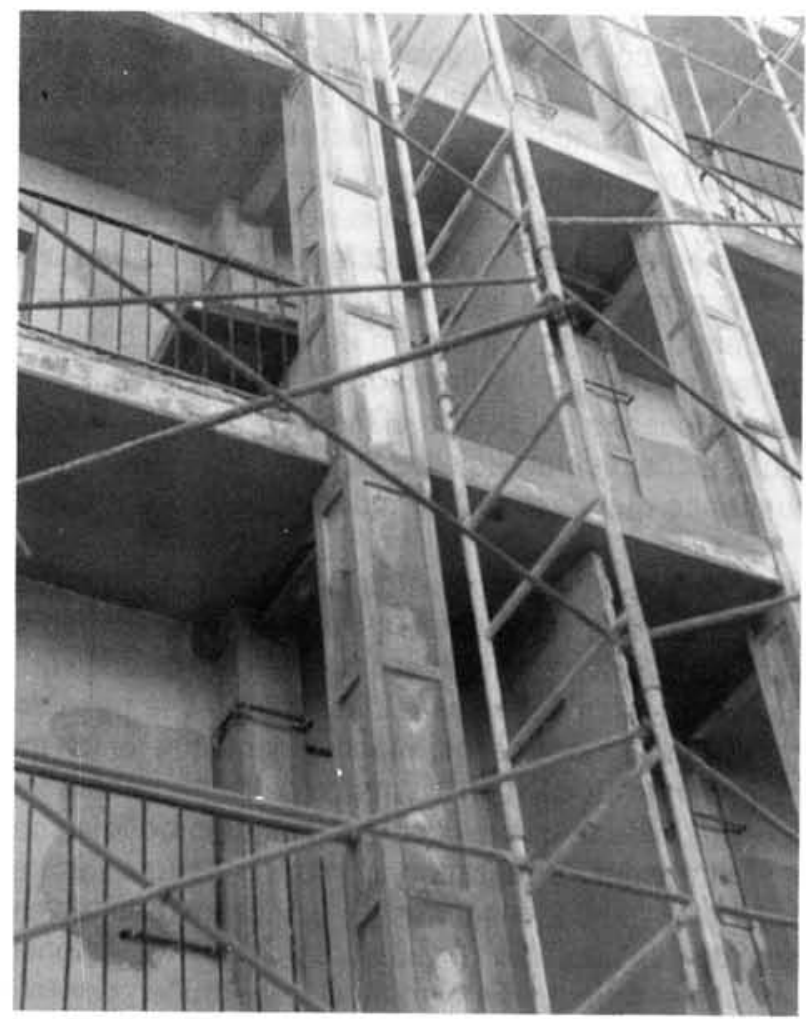

Foto 14.-Zunchado de pilastras y conexiones con el resto de la construcción. Ver fotos 9 y 16.

(c) Consejo Superior de Investigaciones Científicas Licencia Creative Commons 3.0 España (by-nc)

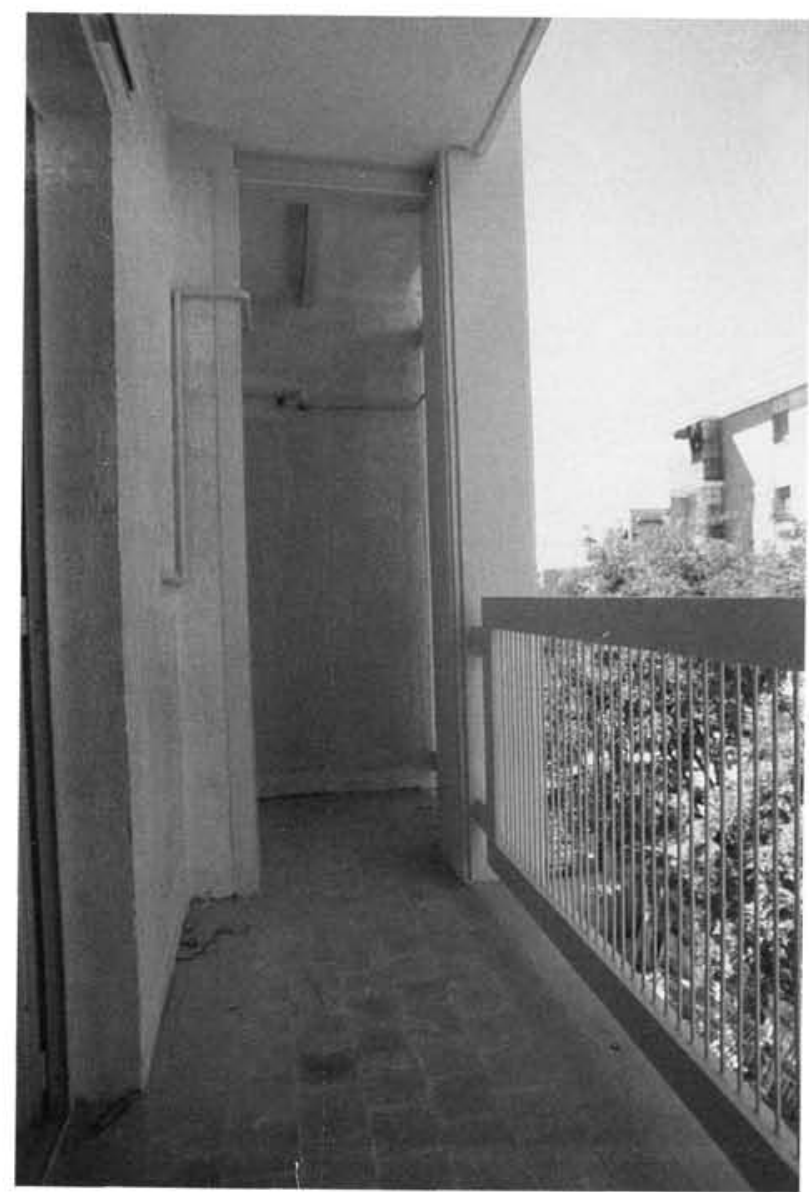

Foto 13.-Zona de terrazas (aspecto final). Se introdujo la conducción de gas ciudad, mejorando los usos y el grado de confort.

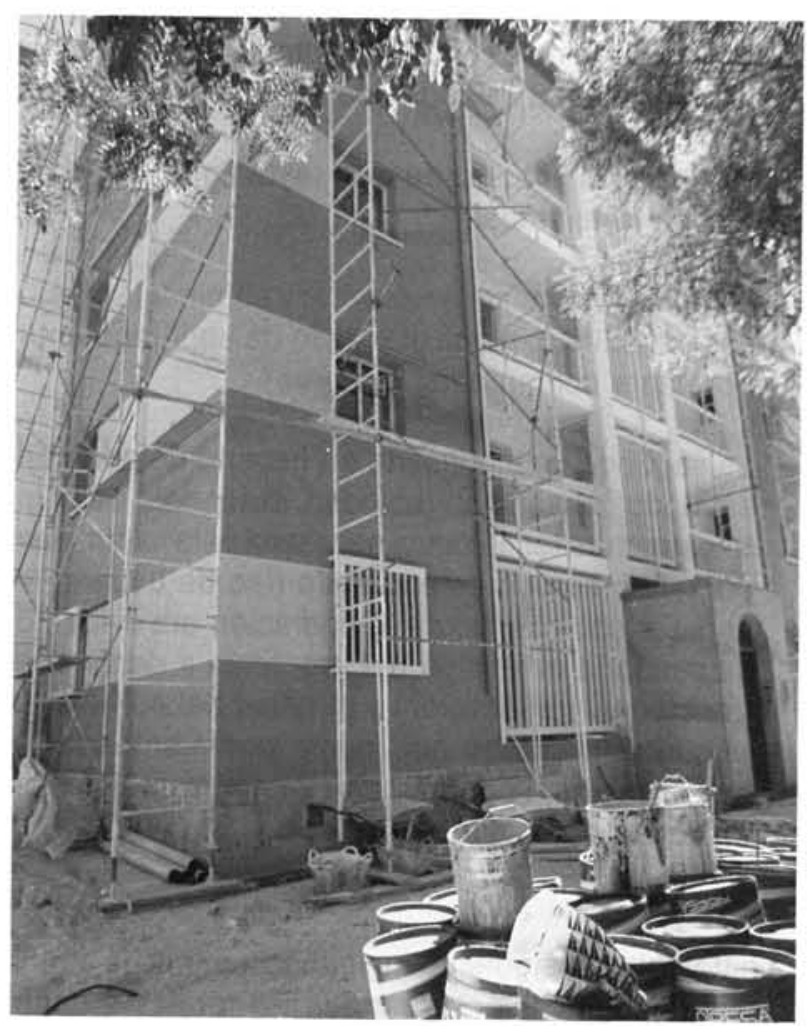

Foto 15.-Aspecto final. Ver foto 16.

http://informesdelaconstruccion.revistas.csic.es 


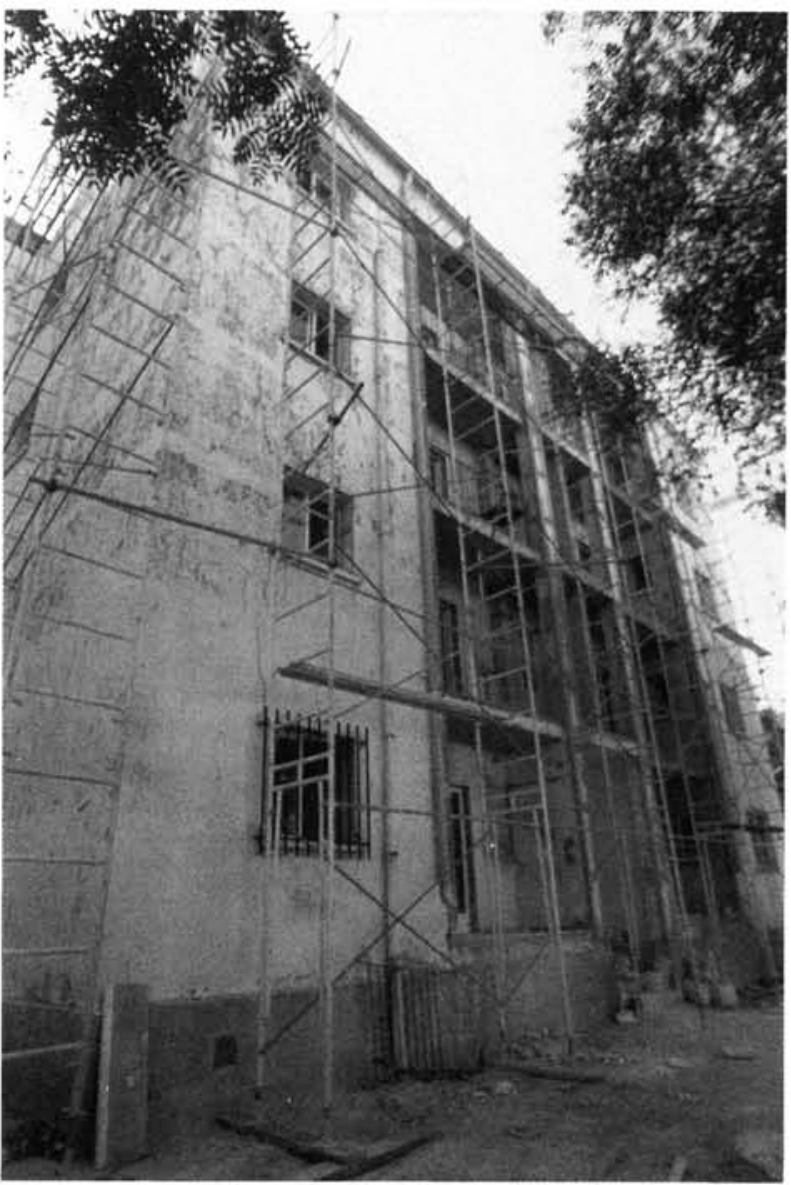

Foto 16.-Fase de reparación de los tendederos y terrazas. Ver fotos 9 y 14

máximo los materiales que deben permanecer y los que aparecerán por necesidades de equilibrio y confort.

En este caso, el proceso de respuesta tiene dos fases claramente diferenciadas:

- La primera consiste en detener y eliminar las lesiones del edificio hasta el estado de equilibrio anteriormente comentado.

- La segunda fase consiste en haberlo dejado consolidado para su habitabilidad, dotándolo de la infraestructura tecnológica necesaria para tal fin, pero contando con un determinado tipo de usuario (el análisis sociológico de la población era evidente) sabiendo la extensión del programa a desarrollar (funciones y utilización) y el papel del edificio en el contexto urbano que, como podrá entenderse, son aspectos fundamentales e imprescindibles en cualquier operación de este tipo.

La patología subsiguiente fue consecuencia de alteraciones traumáticas debido a que las roturas y deformaciones se habian producido por la acción de solicitaciones superiores a las admitidas por los materiales.

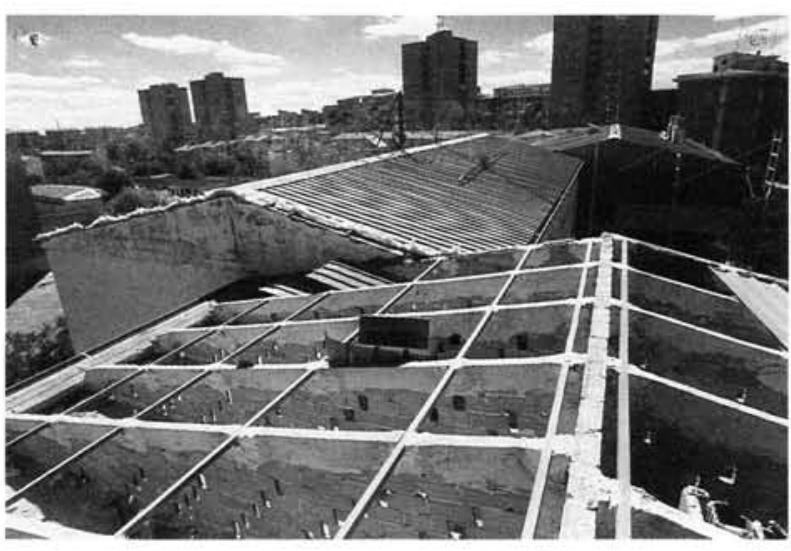

Foto 17.- La actual cubierta se generó de la ya existente, cambiando el sistema de cobertura por otro más duradero y del tipo sandwich que aislara térmica y acústicamente (efecto tambor).

Como es evidente existian lesiones causadas y agravadas por la existencia de pérdidas de resistencia debidas a las patologías y modificaciones funcionales.

La tipología estructural de forjados estaba constituida por viguetas prefabricadas autorresistentes de hor. migón armado con forma de doble T $(19 \mathrm{~cm}$ de canto y $12 \mathrm{~cm}$ de ala), sobre las que apoyaban losas confeccionadas también con hormigón armado, de dimensiones en planta de $50,5 \times 104 \mathrm{~cm}$ y $5 \mathrm{~cm}$ de canto y armadas en forma de retícula con un acabado que daba la terminación final sustituyendo al solado. Estas losas de forjado estaban unidas entre sí mediante un cordón de cemento que recorría todo el perímetro acanalado de las mismas de $2 \mathrm{~cm}$ de diámetro.

Las losas, con las sucesivas entradas de carga, al estar diseñadas para trabajar en forma adintelada y no en arco, tal como trabajan las actuales capas de compresión (recordemos se trata de una construcción experimental, cuyas condiciones económicas están directamente ligadas a la situación actual), sufrian una flecha permamente, levantándose en los apoyos y produciendo fisuras o roturas en la zona central del vano de las mismas, en la dirección de las viguetas. Éstas habian pasado del estado elástico al estado plástico alcanzando muchas de ellas la rotura. Su situación actual hace que sean piezas independientes entre sí.

La carencia de los elementos de atado perimetral de las cabezas de vigueta, en las fábricas que reciben la carga, hacia que sufrieran el apoyo directo de cada una de las viguetas. Estos aspectos, unidos a la poca entrega y, en algunos casos, al poco ancho que tenian los cargaderos situados en los muros de carga, generaban un estado de tensiones desiguales que producian daños puntuales, alcanzando a producir fisuras verticales en los muros (desgarros de fábrica en algunos casos) de considerable tamaño y, en definitiva, lesiones por aplastamiento. Estos daños se producen por fatiga del material: bien por haber alcanzado su limite de resistencia en el tiempo, o por estar sometido a tenhttp://informesdelaconstruccion.revistas.csic.es 


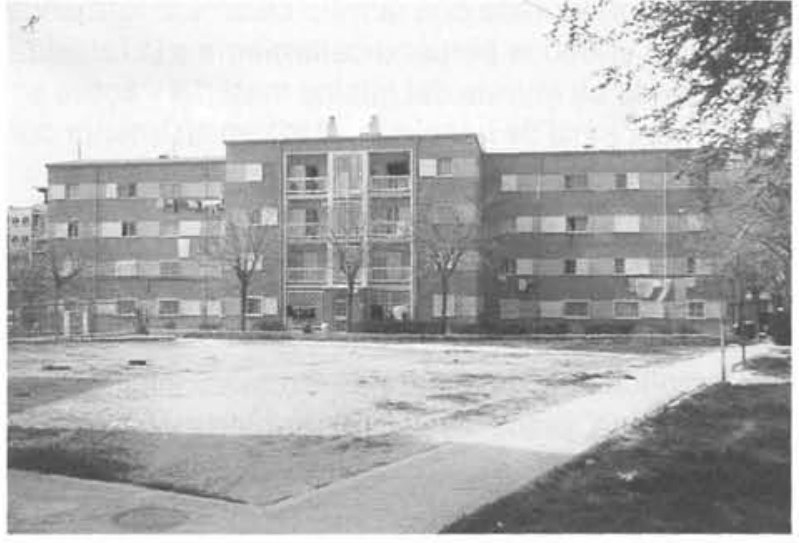

Foto 18.-Aspecto final.

siones superiores a las que es capaz de resistir. En este caso, la función resistente y de transmisión vertical de solicitaciones al terreno está constituida por mu. ros de carga o muros resistentes. Si bien la forma habitual de trabajo de estos muros es a compresión pu. $\mathrm{ra}$, el comportamiento resistente de dichos materiales se caracteriza (si establecemos un diagrama tensión. deformación en un ensayo de compresión pura, Fig. 1) por la ausencia tanto de zona de elasticidad proporcional, como de escalón de relajamiento, por lo que se alcanza el límite de rotura súbitamente (sin previo aviso), asi como para deformaciones unitarias pequeñas, llegando a la rotura a través de un período muy breve de elasticidad. Si a esta forma de trabajo se le añade la falta de reparto de las cargas del forjado (cargas que hay que considerar más bien dinámicas, por las condiciones de libertad en las que se encuentran los elementos del forjado), tenemos las causas de los daños en los muros.

Por otra parte, los tabiques de escayola, con los que se habian hecho las particiones interiores, ante tanto movimiento se encontraban en un estado deplorable.

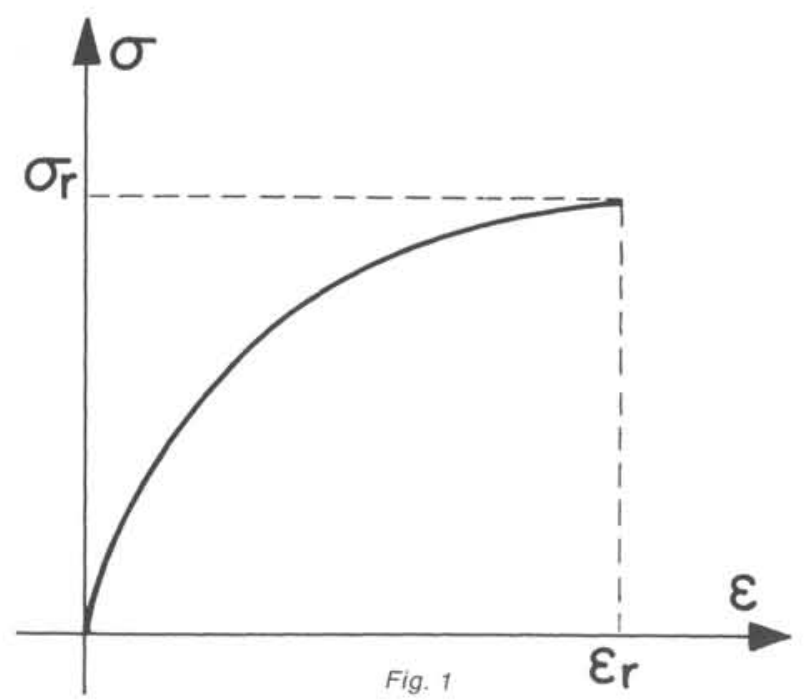

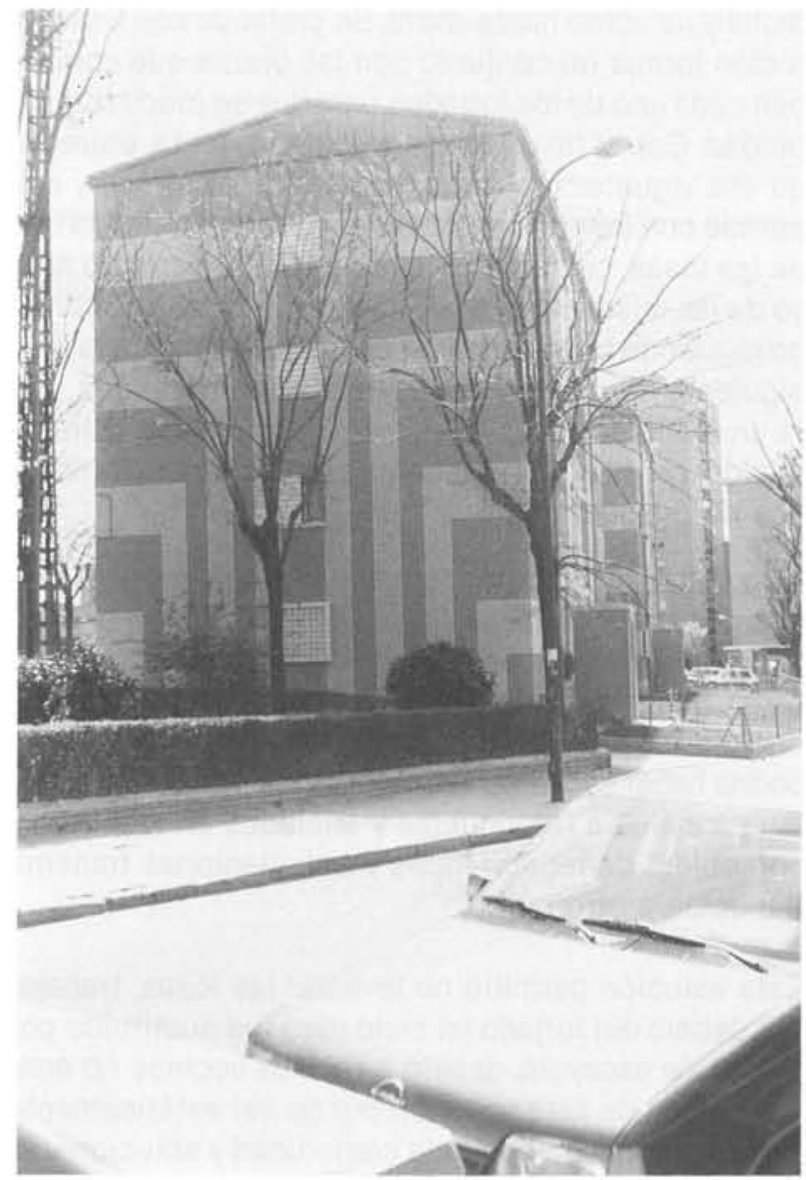

Foto 19.-Aspecto parcial. Se delimitó y ajardinó el terreno comple. tando la intervención.

Hay que tener en cuenta $-y$ esto es muy importante para comprender los daños descritos - que todos los muros de carga de medio pie (la distancia a la que se encuentran entre sí y con los muros de carga de un pie, en el caso más desfavorable, es de 3,96 m) se encuentran en el interior de las viviendas y son los que más dañados se encontraban (fueron reforzados todos). Es muy probable que si esta separación estuviera reducida (en estas mismas condiciones) los daños no serian tan considerables.

A este conjunto de circunstancias se le debe añadir el vertido en el jardin, que las aguas pluviales realizaban de forma directa. Los vecinos, en su dia, acometieron el cambio de funcionamiento de la cubierta (pasó de cubierta plana a dos aguas con canalón y bajantes) sin construir la necesaria red de recogida de las mismas a nivel del suelo. El edificio tenia un pequeño zócalo chapado de piedra, en el cual se formó un aumento de humedad en la fábrica que, en algunos casos, ascendió hasta las viviendas.

La solución de proyecto empleada tiene como objetivo detener el daño de las fábricas e impedir su progresivo deterioro pretendiendo que, en lo posible, el paso de las cargas se efectúe de un modo menos perjui- 
dicial y no como hasta ahora. Se pretende con esta solución formar un conjunto con las piezas que componen cada uno de los forjados para que se produzca una unidad. Con el fin de conseguirlo se ejecuta, entre cada dos viguetas, un revolcón recibido con yeso y ejecutado con ladrillo, macizado entre la clave y cada una de las losas, con objeto de garantizar el perfecto apoyo de las mismas. Esta solución evita que se continúe produciendo la degradación de los forjados con la consiguiente rotura total de las losetas de hormigón, evita un atado entre las viguetas y contribuye a la transmisión, no dinámica, de cargas funcionando como arcos de descarga.

Esta solución se ha considerado la mejor dentro de valoraciones económicas. Otras soluciones, y en concreto aquellas que necesitaban apoyarse en los muros de carga, generaban en si un deterioro de los muros al producirse en éstos numerosas rozas y cajeados, como podría haber sucedido al introducir elementos resistentes paralelos a las viguetas y anclados en los muros, con objeto de reducir luces y solicitaciones transmitiéndolas a otro punto.

Esta solución permitió no levantar las losas, trabajar por debajo del forjado (el cielo raso fue sustituido por placas de escayola, debido a que los vecinos no eran partidarios de esta solución por no ser estéticamente de su agrado) con bastante comodidad y solucionar el problema sin afectar a la estructura portante.

El resto de las obras consistió en sustituir partes ya degradadas por otras nuevas: carpinteria interior y exterior, tabiqueria, armarios empotrados, barandillas, etc., así como las instalaciones totalmente obsoletas y que no garantizaban su buen uso (fontanería, saneamiento), o que no ofrecían los medios apropiados para garantizar seguridad (instalación eléctrica, etc.) se canalizaron por los falsos techos. En las zonas en que las canalizaciones de fontanería aparecian en planos verticales y sobre muro de carga, se adosó un tabique con la finalidad de evitar rozas; en este caso las instalaciones no pudieron ser vistas. Hay que tener en cuenta que socialmente se demandan soluciones tradicionales, comprendiendo con dificultad la prefabricación.

Como medida preventiva para evitar la subida de humedad por los muros de carga de plantas inferiores se realizó un vaciado de tierras hasta por debajo de la actual cimentación, canalizando toda la nueva instalación del saneamiento de fecales que se encontraban en mal estado.

Para evitar problemas de humedad se realizó, a lo largo de todo el perímetro del edificio, una cámara bufa que recogiera las aguas de la escorrentía natural del jardín, albergara la canalización horizontal de aguas pluviales con la acometida vertical de sus bajantes y sirviese como acera de paso alrededor del edificio. Esta cámara fue ejecutada con ladrillo cerámico formando costillares situados perpendicularmente a la fachada, conteniendo un murete del mismo material y sobre solera convencional de hormigón, atada en su interior con un mallazo metálico.

La relación de costos de obra, en \% del total del proyecto de ejecución material, fue la siguiente:
- Demoliciones, desmontajes, excavaciones, albañileria, yesos, escayolas, cubierta y es- calera

- Instalaciones fontanería, electricidad, saneamiento horizontal y vertical

- Solados, alicatados, carpintería y pinturas

- Varios, entre los que se encuentran los gas. tos de desalojo y realojo de los vecinos.

Sin ser significativos estos porcentajes, sí indican la interrelación de los oficios y dan una idea de $10 \mathrm{com}$ plejo que, a veces, es calcular una obra de estas ca. racterísticas.

De todas formas se debe incidir en los siguientes aspectos:

- En primer lugar que toda esta obra fue realizada con un fin experimental, por lo cual así hay que entenderla.

- Que un condicionante importante, en el juicio sobre el estado de esta edificación, es la propia evolución de la Normativa. Afirmación que se podría generalizar, pero que en el caso particular de las construc. ciones con estructura de hormigón armado debe considerarse importante, pues en los últimos 30 años ha experimentado profundos cambios. Los procedimientos de cálculo han variado, sustancialmente, en los últimos 15 años.

- Que en España la evolución de la Normativa se ha realizado, desde 1939, en los siguientes años:

- 1939: Aparición de la Norma para el Proyecto y Ejecución de Obras de Hormigón en Masa o Ar. mado.

- 1968: Aparición de la Norma EH-68.

- 1973: Aparición de la Norma EH-73.

- 1980: Aparición de la Norma EH-80.

- 1982: Aparición de la Norma EH-82.

- 1988: Aparición de la Norma EH-88 y de la Norma EF-88.

http://informesdelaconstruccion.revistas.csic.es 
- Que tal evolución configura cuatro etapas básicas:

- 1. Etapa: Sin normativa especifica. Se aplican tratados básicos y normas extranjeras.

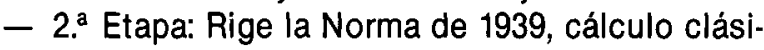
co.

- 3. ${ }^{a}$ Etapa: Normas de cálculo en rotura EH-68, EH-73, EH-80 y EH-82.

- 4. ${ }^{2}$ Etapa: Normativa actualmente vigente. Aparece EF-88.

- Que la mayoria de las normas actuales permiten hacer uso de los recursos plásticos que presentan las estructuras de hormigón armado, cuestión no habitual hace unas décadas. El proyectista actual dispone de medios más potentes y precisos para la realización del cálculo de esfuerzos, no disponibles en épocas precedentes.

- Que, en este caso, la aparición de materiales tales como las losas con acabado, que sustituyen y eliminan a otros materiales, hace comprender el gran esfuerzo por abaratar la construcción. Sin embargo, es- to también es indicativo del posible estudio efectuado para evaluar las cargas que debian de soportar las losas. Su estado evidencia las cargas de utilización del edificio que, en igualdad de condiciones, están en buen estado de conservación y funcionamiento.

- Que la gestión de desalojo de los inquilinos se realizó de forma que cada vivienda fuese adjudicataria de una cierta cantidad de dinero que les permitiese realojarse. Esta fórmula permitió que los vecinos tomaran conciencia de su situación y, a su vez, participaran. El desalojo se llevó a cabo de uno en uno, siendo posible por la independencia constructiva entre los bloques, que permitió se realizara la obra en fases: sucesivamente en el mismo tiempo, y solapándose dos bloques, de forma que cuando estuvo acabado el primero los vecinos volvieron a ocuparlo, aun cuando los otros dos estuvieran en obras. De este modo los costes de desalojos se redujeron. La labor de gestión no fue sólo por parte de la Dirección Facultativa, la Administración -en nuestro caso el I.V.I.M.A.- colaboró eficazmente y facilitó las ayudas necesarias.

\title{
publicación del ICCET/CSIC
}

\author{
ALOJAMIENTO Y TECNOLOGÍA: \\ ¿INDUSTRIALIZACIÓN ABIERTA? \\ Julián Salas Serrano
}

La experiencia nacional en construcción industrializada en la última década, aunque no abundante, puede resultar paralizante. Como reacción, este trabajo trata de elaborar y ordenar la información que, puede resultar paralizante. Como reaccion, este trabajo
pegado al terreno, se ha acumulado durante los sesenta.

Auscultando tendencias avanzadas en otros paises y apoyándose en nuestra realidad cotidiana, el autor Auscultando tendencias avanzadas en otros paises y apoyandose en nuestra realidad cotidiana, el autor lo este en genoral, hasta bien reciente, se ha conocido como contruccion industializada.

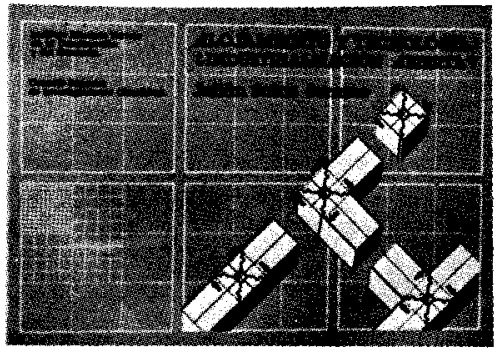

Se abre el trabajo con un prólogo del Profesor Ciribini en el cual, con rigor conceptual y desde su rica experiencia, analiza algunos de los conceptos más polémicos del fenómeno de industrialización del sector construcción. El autor recopila un conjunto de aportaciones de maestros de la arquitectura al lento proceso de evolución tecnológica y conceptual, continuando con un intento de respuesta realista a la interrogante que flota en el sector nacional: ¿réquiem por la industrialización?

Se dedican otros capítulos a revisar lo realizado y a encarar el futuro inmediato: el concepto de componente, su repercusión económica, la dificultad del proyecto a base de productos industriales, la nueva vigencia embrionaria de la construcción por medio de catálogos, los conceptos de flexibilidad e intercambiabilidad desde una óptica práctica... Especial atención dedica este trabajo a la exposición de lo que podiamos llamar nuevos derroteros de la coordinación dimensional, aportando una visión actualizada y pragmática de los enfoques más implantados en Europa.

Las siempre problemáticas interrelaciones entre normativa, calidad e industria se detallan de forma documentada y realista. Finaliza el trabajo con unas reflexiones dirigidas al ámbito empresarial y un esbozo de "reglas de juego" que faciliten al subsector la salida del «impasse» actual.

Un volumen encuadernado en rústica, de $24 \times 16,5 \mathrm{~cm}$, compuesto de 160 páginas, con 109 figuras, 19 tablas y 86 referencias bibliográficas. Madrid, junio, 1981 . 